Pak. j. sci. ind. res. Ser. B: biol. sci. 2020 63B(1) 17-21

\title{
Efficacy of Bio-Insecticides and Synthetic Insecticides on the Control of Helicoverpa armigera Insect on Tomato Crop
}

\author{
Taimur Ahmad*, Rasool Khana, Mazhar Ullah", Tariq Nawaz Khattak ${ }^{\mathrm{b}}$, Imtiaz Ahmad ${ }^{\mathrm{d}}$, \\ Ihsanullah $^{\mathrm{b}}$, Ayaz Khan ${ }^{\mathrm{a}}$ and Saleem Khan ${ }^{\mathrm{a}}$ \\ ${ }^{a}$ Institute of Chemical Sciences, University of Peshawar, \\ ${ }^{b}$ Nuclear Institute for Food and Agriculture, NIFA, Peshawar. \\ ${ }^{\mathrm{c}}$ Agricultural University Peshawar. \\ ${ }^{\mathrm{d}}$ Bacha Khan University Charsadda
}

(received February 13, 2018; revised June 16, 2018; accepted July 6, 2018)

\begin{abstract}
A field study was conducted to investigate the effect of botanical extracts i.e. neem oil emulsified with NIFA adjuvant, turmeric and hinge crude extracts and neem oil in combination with white oil emulsified with NIFA adjuvants and the synthetic insecticides i.e. emamectin and bifenthrin on the control of Helicoverpa armigera on tomato crop. It was found that the highest control of $H$. armigera was observed for emamactin and the lowest was recoded for control. Similarly, the highest yield of tomato was recoded for neem-white oil treatment and lowest infestation was recorded for emamactin benzoate. The neem oil and neem oil in combination with white oil emulsified with NIFA adjuvant also showedbetter results than bifenthrin and hinge and turmeric crude extracts in controlling the larvae population of $H$. armigera. On the basis of these findings, neem oil and neem oil combined with white oil is the best management technique for controlling the $H$. armigera, as these agents pose least environmental hazards and are relatively nontoxic to beneficial insects and humans and readily photodegrade.
\end{abstract}

Keywords: adjuvant, botanical extracts, tomato borer, neem oil, white oil.

\section{Introduction}

Tomato is an important vegetable grown throughout the world (Jat and Ameta, 2013). In Pakistan this vegetable is grown in large area (Mari et al., 2007). The tomato plant is attacked by various insect pest which cause a great damage to plant and economical loss to the farmers (Meena and Raju, 2014; Chowdary et al., 2010). Helicoverp armigera or tomato borer is a major pest of tomato crop, responsible for a decrease in tomato production (Wagh et al., 2012 and Geiger et al., 2010). Helicoverp armigera is a polyphagous pest and can infest a large number of crops and lower the market value of vegetable crops (Prasanna et al., 2013). The $H$. armigera can cause a mark decrease in the yield of tomato (Gajete et al., 2004). Synthetic insecticides are commonly used for the control of this pest, but this insect has developed resistance to a large number of synthetic pesticides (Gandhi et al., 2013; Kaur et al., 2013). Besides, the synthetic pesticides are toxic to non-target insects and are not easily degraded and their residues may accumulate in the food chain and may be toxic to humans (Damavandian, 2010). So efforts are being made to find the alternate pest management

*Author for correspondence; E-mail: taimurjf@yahoo.com strategies to overcome the harmful effects of the synthetic pesticides. Botanical extracts notably the neem oil and paraffinic, white mineral oilare relatively safe alternative to synthetic insecticides because neem products rapidly degrade and is target specific.

The present study was carried out to see the effect of neem oil and white paraffinic oil emulsified with NIFA developed adjuvant, turmeric and hinge crude extracts and the synthetic pesticides such as emamactin and bifenthrin on tomato crop for the control of $H$. armigera.

\section{Materials and Methods}

Design of experiment. The field study was carried out at the tomato field situated in Pabbi station Nowshera. The experiment was carried out in the randomized complete block design, RCBD. The field was divided into seven plots with three replications. The distance between the plants was seventy $\mathrm{cm}$ and a row to row distance of one meter was maintained. The size of each plot was sixteen $\mathrm{m}^{2}$. Shimla variety of the tomato was sown. The plantation was carried out in $3^{\text {rd }}$ week of March 2017.

Treatments. The synthetic insecticides were purchased from the local market in Peshawar. The neem oil was 
extracted by cold press method and emulsified with NIFA adjuvant. The turmeric and hinge extracts were prepared using the procedure of Munir (2006). The neem oil was mixed with white oil in a ratio of $4: 6$ and the emulsified with NIFA adjuvant and a paste was developed. The following treatments were applied three times during the whole experiment in the field against the Helicoverpa armigera (Table 1).

Table 1. Different treatments and their percentage concentration

\begin{tabular}{ll}
\hline \hline Treatments & \% Concentration \\
\hline $\begin{array}{l}\text { Neem oil emulsified with NIFA adjuvant } \\
(3 \%)\end{array}$ & 3 \\
$\begin{array}{l}\text { Neem-white oil emulsified with NIFA } \\
\text { adjuvant }\end{array}$ & 3 \\
Hinge crude extract & 3 \\
Turmeric crude extract & 5 \\
Emamectin benzoate & 2.5 \\
Bifenthrin & 2.5 \\
Control (no application) & \\
\hline \hline
\end{tabular}

Data collection. The population of larvae of $H$. armigera was recorded on weekly basis. The insecticides were applied at an interval of fifteen days. Ten plants were selected in each plot for the observation of larvae. The percent protection of the fruit over the control was determined using the following formula, $\%$ protection over control $=\mathrm{C}-\mathrm{T} / \mathrm{C}$

where:

$\mathrm{C}=\%$ fruits damaged in control; $\mathrm{T}=\%$ fruits damaged in treatment.

The percent reduction in larval population was determined using Abbots formula developed in 1925 and is given as;

$\%$ Reduction $=\mathrm{C}-\mathrm{T} / \mathrm{C} \times 100$. where:

$\mathrm{C}=$ larvae population in control; $\mathrm{T}=$ larvae population in treatment.

Similarly, the yield of tomato for each plot was determined and increase in yield over control was determined for each treatment.

Data analysis. The results were subjected to one-way ANOVA followed by Dunnett post hoc test.

\section{Results and Discussion}

Effects of treatments on larvae population. The results obtained regarding the population of $H$. armigera per plant of tomato after the application of the pesticides in each treatment are shown in Table 2. All the treatments of the insecticides were found superior over control. It is apparent from the table that lowest mean population of larvae 0.96 per plant was observed for emamectin benzoate treatment and the highest population of larvae per plant was recorded for control and was 1.66. The emulsified neem treatment has 1.12, neem-white oil has 1.06 , hinge crude extract has 1.33 , turmeric crude extract has 1.26 , while bifenthrin has 1.28 larvae of $H$. armigera per plant respectively. There was a gradual decrease in larvae population plant after each week. In second week, the lowest larval population was recorded for neem treatment and was 0.81 larvae per plant and the highest larvae were recorded for control. In third week, the number of $H$. armigera further reduced in all the treatment except turmeric crude extract which has a slight increase in larval population and was 1.1 larvae per plant (Fig. 1). The lowest larval population was recorded for emamectin benzoate treatment and was 0.66 larvae per plant. The larvae per plant after third week were $0.75,0.82,0.1 .05,0.93$ and 1.7 for neem, neem-white oil, hinge crude extract, turmeric crude extract, emamectin benzoate, bifenthrin and control

Table 2. Population of $H$. armigera on tomato plant in each treatment on week basis.

\begin{tabular}{llllllll}
\hline \hline Treatments & $1^{\text {st }}$ Weak & $2^{\text {nd }}$ Weak & $3^{\text {rd }}$ Weak & $4^{\text {th }}$ Weak & $5^{\text {th }}$ Weak & $6^{\text {th }}$ Weak & $\begin{array}{l}\% \text { larvae } \\
\text { reduction }\end{array}$ \\
\hline T1 & $1.12 \pm 0.62^{\mathrm{NS}}$ & $0.81 \pm 0.46^{\mathrm{NS}}$ & $0.75 \pm 0.36^{\mathrm{NS}}$ & $0.55 \pm 0.41^{* *}$ & $0.41 \pm 0.40^{* *}$ & $0.20 \pm 0.26^{* *}$ & 59 \\
$\mathrm{~T} 2$ & $1.06 \pm 0.58^{\mathrm{NS}}$ & $0.93 \pm 0.40^{\mathrm{NS}}$ & $0.82 \pm 0.75^{\mathrm{NS}}$ & $0.41 \pm 0.18^{* *}$ & $0.33 \pm 0.30^{* *}$ & $0.00 \pm 0.00^{* *}$ & 62.1 \\
$\mathrm{~T} 3$ & $1.33 \pm 0.61^{\mathrm{NS}}$ & $1.12 \pm 0.69^{\mathrm{NS}}$ & $1.05 \pm 0.47^{\mathrm{NS}}$ & $0.96 \pm 0.41^{\mathrm{NS}}$ & $0.91 \pm 0.46^{\mathrm{NS}}$ & $0.77 \pm 0.25^{* *}$ & 34.6 \\
$\mathrm{~T} 4$ & $1.26 \pm 0.67^{\mathrm{NS}}$ & $1.03 \pm 0.55^{\mathrm{NS}}$ & $1.1 \pm 0.46^{\mathrm{NS}}$ & $0.88 \pm 0.60^{*}$ & $0.81 \pm 0.80^{\mathrm{NS}}$ & $0.63 \pm 0.45^{* *}$ & 39.1 \\
$\mathrm{~T} 5$ & $0.96 \pm 0.55^{\mathrm{NS}}$ & $0.89 \pm 0.26^{\mathrm{NS}}$ & $0.66 \pm 0.31^{\mathrm{NS}}$ & $0.53 \pm 0.50^{* *}$ & $0.21 \pm 0.20^{* *}$ & $0.00 \pm 0.0^{* *}$ & 65.3 \\
$\mathrm{~T} 6$ & $1.28 \pm 0.30^{\mathrm{NS}}$ & $0.950 .45^{\mathrm{NS}}$ & $0.93 \pm 0.64^{\mathrm{NS}}$ & $0.71 \pm 0.26^{* *}$ & $0.44 \pm 0.40^{* *}$ & $0.33 \pm 0.33^{* *}$ & 50.6 \\
T7 (Control) & $1.66 \pm 0.76$ & $1.83 \pm 0.76$ & $1.7 \pm 0.61$ & $1.91 \pm 0.36$ & $2.10 \pm 1.01$ & $1.90 \pm 0.36$ & - \\
\hline \hline
\end{tabular}

$\mathrm{NS}=$ Non-significant, ${ }^{*}=$ Significant; at á $<0.05 ; * *=$ Significant at á $<0.01$ 


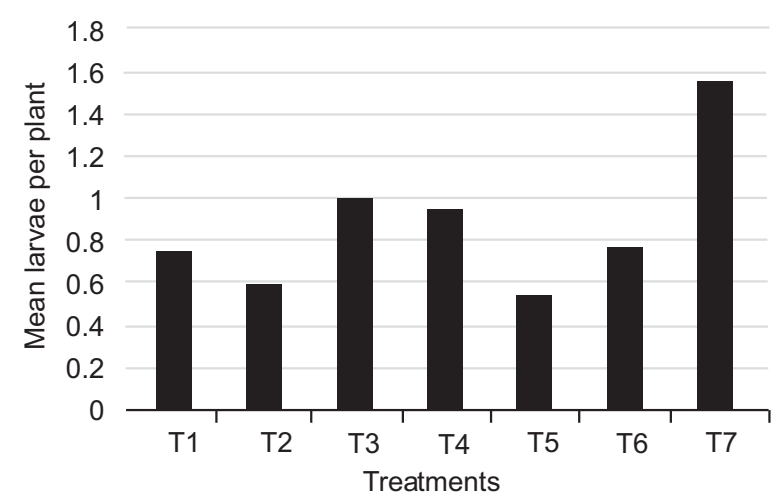

Fig. 1. Mean larvae per plant

treatments respectively. Data collected after fourth week indicates that neem-white oil has lower larvae population per plant as compared to all other treatments and was found to be 0.41 larvae per plant shown in Fig. 2. All the treatments have lower larvae population of $H$. armigera than those recorded after the third week. The highest larvae were recorded for control and was 1.91. Neem oil and emamectin benzoate have almost the same number of larvae per plant and were 0.55 and 0.53 respectively. The larvae per plant were 0.96 and 0.88 respectively for hinge and turmeric crude extract treatments. After fifth week the number of larvae further reduced in all the treatments and the reduction in larval population was more pronounced in case emamectin benzoate treatment, where the number of $H$. armigera was 0.21 per plant and control has the highest larvae population per plant and was found to be 0.91 . The sixth week data shows that larvae population were significantly lowered by the insecticides and all the treatments have the lowest larval population than the previously recorded data and no larvae were found in case of neem-white and emamectin benzoate treatments and neem oil treatment has a larvae population of 0.2 per plant. The highest number of $H$. armigera per plant was 0.77 per plant recorded for bifenthrin treatment. The lowest mean larvae population was recorded for emamectin treatment and was 0.54 and the highest mean value was recorded for hinge treatment and was 1.02. neem-white oil treatment showed next best results after emamectin benzoate and next to this treatment was neem oil treatment having mean values of 0.59 and 0.64 respectively. The percent larvae reduction over control was the highest for emamectin treatment and was 65.3 and lowest was recorded for hinge crude extract treatment and was 34.6 (Fig. 2).

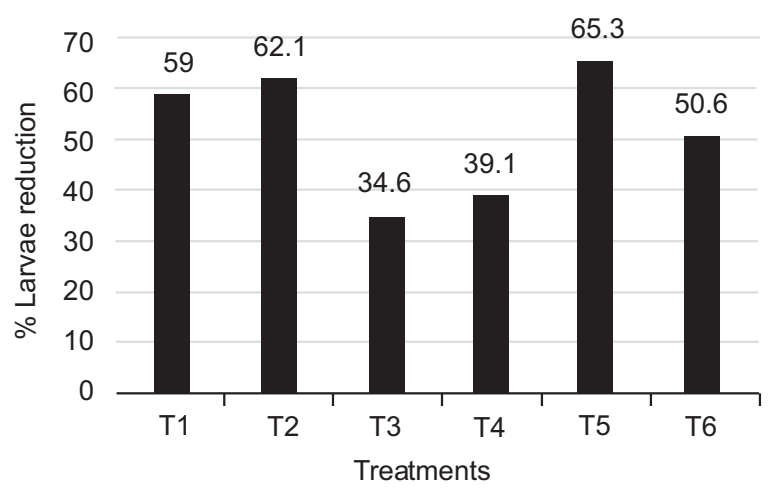

Fig. 2. Percent larvae reduction over control

Fruit infestation and yield parameters. The highest yield of tomato was recorded for neem-white oil treatment and was $583 \mathrm{~kg}$ (Fig. 3). Neem oil and emamectin benzoate have almost the same total yield and was 560 and $570 \mathrm{~kg}$ respectively. Amongst the six treatment, the lowest yield was recorded for hinge crude extract treatment and was $525 \mathrm{~kg}$. The yield of tomato for control was $463 \mathrm{~kg}$. Similarly, the lowest infestation in tomato fruits were recorded for emamectin benzoate and was 4.2 percent and the highest damage was observed control and was 17.33 percent, shown in Table 3 and Fig. 3.

The present findings are in close agreement with the data taken by Shah et al. (2013) who reported that neem extract has nearly the same action as that of emamectin benzoate in controlling the $H$. armigera on tomato. They found that mean number of $H$. armigera per plant were 0.40 and 0.46 for emamactin and neem treatments respectively. They also found that highest yield of tomato $(7540 \mathrm{~kg})$ was recorded for neem treatment and

Table 3. Damaged fruits and overall yield of tomato for each treatment.

\begin{tabular}{|c|c|c|c|c|}
\hline $\begin{array}{l}\text { Treat } \\
\text { ments }\end{array}$ & $\begin{array}{l}\text { Mean } \% \\
\text { Damaged } \\
\text { fruits }\end{array}$ & $\begin{array}{l}\% \text { Protection } \\
\text { over control }\end{array}$ & Yield (kg) & $\begin{array}{l}\text { \% Increase } \\
\text { over } \\
\text { control }\end{array}$ \\
\hline $\mathrm{T} 1$ & $5.1 \pm 1.01 * *$ & 70.5 & $560 \pm 8.71 * *$ & 18.76 \\
\hline $\mathrm{T} 2$ & $4.66 \pm 2.20 * *$ & 71.74 & $583 \pm 11.79 * *$ & 22 \\
\hline $\mathrm{T} 3$ & $7.8 \pm 2.25 * *$ & 55 & $525 \pm 13.23 * *$ & 13.33 \\
\hline $\mathrm{T} 4$ & $4.9 \pm 1.01 * *$ & 71.7 & $538 \pm 9.84 * *$ & 15.4 \\
\hline T5 & $4.2 \pm 1.05 * *$ & 75.7 & $570 \pm 13.23 * *$ & 20.1 \\
\hline T6 & $4.8 \pm 1.05 * *$ & 72.3 & $553 \pm 9.85^{* *}$ & 17.72 \\
\hline $\mathrm{T} 7$ & $17.33 \pm 3.05$ & - & $455 \pm 4.36$ & - \\
\hline
\end{tabular}




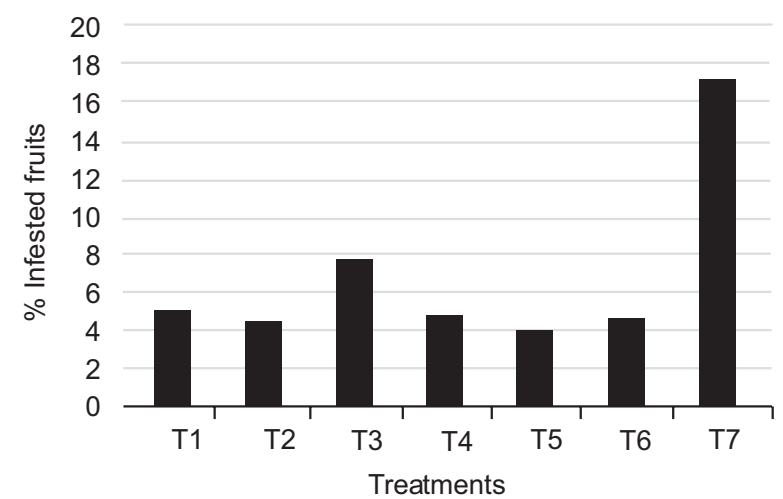

Fig. 3. Percent infested tomato fruits

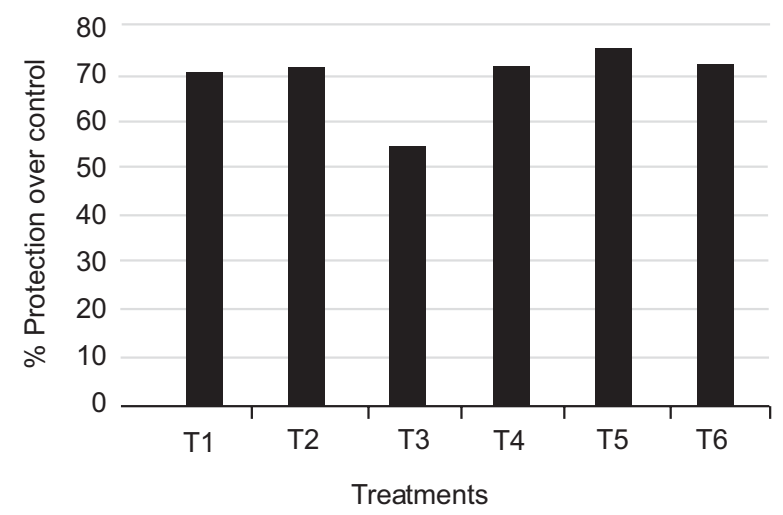

Fig. 4. Percent protection over control

the next high yield was recorded for emamactin benzoate (7300 kg). Packiam et al. (2012) found that Pon neem showed high oviposition deterrent property. Phukon et al. (2014) reported that neem oil was as much effective as cypermethrin in controlling the fruit damage by H. armigera and noted 92.20 percent reduction in fruit damage for cypermethrin and $91.12 \%$ reduction for neem treatments respectively. They also noted that neem oil was the next superior treatment after cypermethrin in increasing the yield of tomato over the control treatment which is shown in Fig. 4.

Rijal et al. (2008) reported that neem oil yielded second highest production of chick pea after cypermethrin. Elshafie and Abdelraheem (2012) reported that neem treatment has a significant effect in the yield of tomato over control. shown in Fig. 5. Hedge (2004) applied $5 \%$ neem seed kernel extracts (NSKE) on okra plants and observed the lowest number of larvae of pod borer per plant.

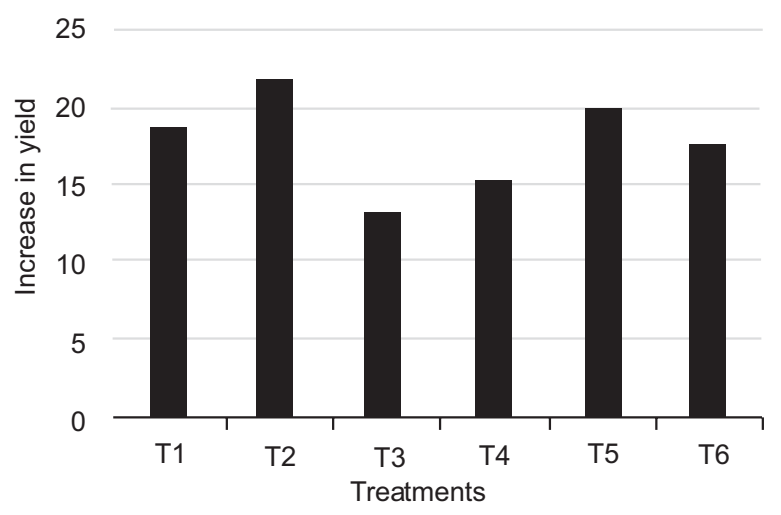

Fig. 5. Increase in yield over control

Udikeri et al. (2004) noticed that emamectin was a better agent to control the cotton bollworms and their finding confirms the present study.

\section{Conclusion}

The present study reveals that the neem oil and its combination with white oil showed good results for the control of $H$. armigera on tomato crop. These biopesticides are the excellent alternatives of the synthetic peticides and can be effectively applied as IPM strategy in order to lower the inputs of toxic synthetic chemical pesticides. Further study is recommended on these biopesticides on other crops for the control of other insect pests.

\section{Acknowledgement}

We are highly thankful for the kind support of Dr. Tariq Nawaz Khattak of Nuclear Institute for Food and Agriculture Peshawar for providing chemicals and useful instructions.

Conflict of Interest. The authors declare no conflict of interest

\section{References}

Chowdary, L.R., Bheemanna, M., Kumar, L.R. 2010. Bio-efficacy of rynaxypyr (Coragen) $20 \mathrm{SC}$ against fruit borer Helicoverpa armigera (Hubner) in Okra. International Journal of Plant Protection, 3: 37981.

Damavandian MR. 2010. Comparison of current insecticides with mineral oil for the control of Pulvinaria aurantii Comstock in Mazandaran citrus orchards and their efficacy on phytoseiid mites. Applied 
Entomology and Phytopathology, 78: 81-97.

Elshafie, H.A.F., Abdelraheem, B.A. 2012. Field evaluation of three biopesticides for integrated management of major pests of tomato, Solanum lycopersicum L. in Sudan. Agricultural and Biological Journal of North America, 3: 340-344.

Gajete, T.D., Gajete, L.B., Irabagon, J.R., Tiburcio, E.B. 2004. Techno-guide for tomato production. In: Techno-guides for Agriculture Production and Livelihood Projects. CLSU Research Office, RET, pp. 58-65. Science City of Muñoz, Nueva Ecija.

Gandhi, B.K., Shekharappa, Balikai, R.A. 2013. Bioefficacy of insecticides in management of Helicoverpa armigera (Hubner) in Kharif sorghum. Annals of Plant Protection Science, 21: 83-86.

Geiger, F., Bengtsson, J., Berendse, F., Weisser, W.W., Emmerson, M., Morales, M.B., Ceryngier, P., Liira, J., Tscharntke, T., Winqvist, C., Eggers, S. 2010. Persistent negative effects of pesticides on biodiversity and biological control potential on European farmland. Basic and Applied Ecology, 11: 97-105.

Hegde, K.K. 2004. Eco-friendly approaches in the management of Okra fruits borers. M.Sc (Hons.) Thesis, University of Agricultural Sciences. Dharwad. 82p.

Jat, S.K., Ameta, O.P. 2013. Relative efficacy of biopesticides and newer insecticides against Helicoverpa armigera (hub.) in tomato. The Bioscan, 8: 579-582.

Kaur, Sandeep, Subash, Singh. 2013. Field efficacy of some systemic insecticides and microbial pesticides (modules) against aphid, Aphis gossypii glover and fruit borer, Helicoverpa armigera (hubner) on tomato in Punjab. Agriculture Sustainable, 1: 1-6.

Meena, L.K., Raju, S.V.S. 2014. Bio-efficacy of newer insecticide sagainst tomato fruit borer, Helicoverpa armigera (hubner) on tomato, Lycopersicon esculentum Mill under field conditions. The Bioscan, 9: 347-350.

Mari, F.M., Rajab, A.M., Lohano, H.D. 2007. Measuring returns to scale for onion, tomato and chilies production in Sindh province of Pakistan. Inter- national Journal of Agriculture and Biology, 9: 788-790.

Munir, K. 2006. Efficacy of different plant crude extracts for the control of insect pests of okra. M.Sc. (Hons.) Thesis, The University of Agriculture., Peshawar, Pakistan.

Packiam, S.M., Veeramuthu, A., Savrimuthu, I. Vendan, S. E. 2012. Formulation of a novel phytopesticide PONNEEM and its potentiality to control generalist herbivorous lepidopteran insect pests, Spodoptera litura (Fabricius) and Helicoverpa armigera (Hubner) (Lepidoptera: Noctuidae). Asian Pacific Journal of Tropical Disease (Supplement 2): S720S723.

Prasanna, k.N., Chakravarthy, A., Kumar, L.V. 2013. Relationship between pheromone trap catches and field damage of selected lepidopterous pests on vegetable crops. Pest Management in Horticultural Ecosystem, 15: 63-67.

Rijal, J.P.Y.D., Thapa, R.B.G.C., Kafle, L.N. 2008. Comparative efficacy of insect pathogenic fungi Metarhijium anisopliae and Beauveria bassiana against to Helicoverpa armigeria in Chickpea, under Field conditions of Nepal. Formosan Entomologist, 28: 249-259

Sarma, I., Phukon, M., Borgohain, R., Sarma, B., Goswami, J. 2014. Response off French been (Phaseolus Vulgaris L.) to organic manure, Vermicom post and biofertilzers on growth parameters and yield. The Asian Journal of Horticulture, 9: 386-389.

Shah, J.A., Inayatullah, M., Sohail, K., Shah, S.F., Shah, S., Iqbal T., Usman, M. 2013. Efficacy of botanical extracts and a chemical pesticide against tomato fruit worm, Helicoverpa Armigera (Lepidoptera: Noctuidae). Sarhad Journal of Agriculture, 29: $93-$ 96.

Udikeri, S.S., Patil, S.B. Rachappa, V. Khadi, B.M. 2004. Emamectin benzoate 5 SG: a safe and promising bio-rational against cotton bollworms. Pestology, 6: 24-27.

Wagh, S., Patil, P., Lad, S., Patil, S. 2012. Eco-friendly management of tomato pests. International Journal of Plant Protection, 5: 45-48. 